\title{
Fuzzy Fatigue Reliability Analysis and Optimization of A-Type Frame of Electric Wheel Dump Truck Based on Response Surface Method
}

\author{
Chengji MI*, Wentai LI**, Wenguang WU***, Xuewen XIAO**** \\ *Department of Mechanical Engineering, Hunan University of Technology, Zhuzhou, China; State Key Laboratory of Ad- \\ vanced Design and Manufacture for Vehicle Body (Hunan University), Changsha, China, \\ E-mail: michengji_86@126.com \\ **Department of Mechanical Engineering, Hunan University of Technology, Zhuzhou, China, \\ E-mail:915074956@qq.com \\ ***Department of Vehicle and Mechanical Engineering, Changsha University of Science \& Technology, Changsha, \\ China, E-mail:297128708@qq.com \\ ****Department of Mechanical Engineering, Hunan University of Technology, Zhuzhou, China, \\ E-mail:576921249@qq.com \\ crossref http://dx.doi.org/10.5755/j01.mech.25.1.21726
}

\section{Introduction}

The electric wheel dump truck usually runs under extremely poor conditions and has to continuously work for around more than ten hours a day with heavy loads [1]. Due to many bends on the mine road surface, the electric wheel dump truck turns frequently, which easily leads to some structure occurring fatigue failure in the steering system. The A-type frame is considered as one of main bearing components, and thence its fatigue reliability should be ensured, which is directly related with truck's safely running [2].

The A-type frame is welded by high strength steel plates with different thickness. This forming process results in many uncertainties of mechanical properties in the elastoplastic stage, such as Young's modulus $E$, cyclic strengthening coefficient $K^{\prime}$ and fatigue strength et al [3]. In the meanwhile, the random load at connection sites between Atype frame and frame is caused by the random road surface roughness when the electric wheel dump truck runs on the mine road surface. Therefore, the fatigue reliability of Atype frame is provided with fuzziness because of the randomicity of the material properties and loads [4]. Then, based on the response surface method, the fatigue reliability of A-type frame in the electric wheel dump truck was implemented with fully considering uncertainties of material properties in the manufacturing process and uncertainties of loads in the usage.

In recent years, the machinery equipment tends to be high speed, huge dimension and intelligence, so that many researchers gradually focus on fatigue reliability of large heavy equipment. Huang et al [5] proposed a mathematic model for describing the fatigue failure behavior of a tension shaft in the turbofan engine, combined the finite element method with the Miner linear cumulative damage rule. According to the standard load spectrum, its damage was calculated, and the feasibility of this fatigue life prediction method was verified. However, the structural material properties and loads are definitive in the research mentioned above, while the influence of uncertain factors on fatigue reliability analysis is not considered. Yang et al [6] thought that the uncertainties of wave loading had large proportions in analysis of structural fatigue strength for ocean platform. The uncertainties estimation formulas of wave loading caused by wave spectrum, sea wave height, wave loading transfer function, cross-zero period, sea state occurring possibility and wave direction were built to calculate structural fatigue reliability. Wang et al [7] considered uncertain material properties, geometry dimension and load as random variables. The fatigue reliability estimation method was proposed to calculate the reliability of random structure, based on the modified first-order second-moment method and finite element method. The only load is considered as uncertain factor in the previous researches mentioned above, but the material properties are also unsetting because manual welding process had randomness for the welded structures. The fatigue life prediction of welded A-type frame under severe working conditions and special structure was conducted by the author Gao [8], taking advantage of experimental work and uncertain theory. In the previous work mentioned above, even though the uncertainties of material parameters in the manufacturing process and loads in the usage are both considered to analyze the fatigue reliability of weld material, its performance function could not be clearly presented and the fatigue reliability assessment and optimization method of weld material still needs to be explored. Based on the interval optimization method, fatigue life interval optimization analysis model with two types of welded structures: tensile-shear and modified tensile shear spot welded joints was constructed by the author Liu et al [9]. The corresponding upper and lower fatigue life bounds of the standard sample welded structures were also demonstrated. A research approach for fatigue life limit analysis and optimal design of spot welded structures in engineering practices was provided. Those researches all provide some references for fuzzy fatigue reliability analysis and optimization of weld A-type frame in this paper. Because the welded A-type frame has complex structure, varying random load and disperse material parameter, the key point in this paper is to establish fuzzy fatigue reliability calculation method in line with engineering practical problems.

In this paper, taking full consideration of material and load's uncertainties, the fatigue reliability analysis of welded A-type frame is implemented based on response surface method and fuzzy theory. The material properties of welding seam are firstly obtained from the experimental work. The load information of pivotal connection sites of Atype frame was obtained by the rigid and flexible coupling 
multi-body dynamics analysis for the whole vehicle. The finite element model of A-type frame with welding details was constructed, and its accuracy was verified by stress test on the mine road surface. Then, the material parameters and load information of welded A-type frame were taken as random variables and fatigue limit was regarded as a fuzzy variable. The random variables were sampled by the Latin hypercube method, and the corresponding response values were obtained by the elastic and plastic finite element simulation under cyclic loadings. The fatigue reliability performance function of A-type frame was constructed based on the response surface method. Finally, based on fuzzy theory, the fatigue reliability performance of A-type frame under the condition of downhill and turning braking with full load was evaluated, and the optimal design was performed by genetic algorithm.

\section{Local cracks of welded A-type frame}

The electric wheel dump truck often runs at large open mineral site, and there are many potholes and bends on the mine road surface, so that it has to turn frequently. The A-type frame is considered as main bearing component in the steering system, and the local welding seam cracks happen at the early service period, caused by the random loads from random road surface roughness, as shown in Fig. 1. According to the actual investigation reports from mineral site, it only takes 1.3 years to produce visible cracks at several weld toes. The cracks belong to fatigue failure after preliminary analysis and identification, which apparently could not meet service life requirement for engineering practical structure. Therefore, the fatigue reliability analysis and optimization of welded A-type frame are needed.

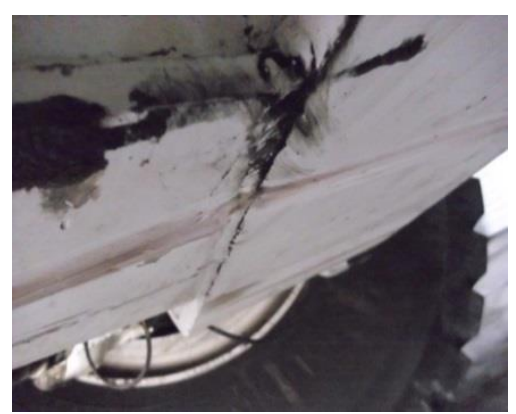

Fig. 1 Visible Welding seam cracks of A-type frame

\section{Experimental work}

\subsection{Specimens production}

Flat dog-bone shaped specimens used for both tensile and cyclic tests were designed to be $6 \mathrm{~mm}$ thick, because the welding seam at the middle of specimen required some thickness to be welded and fatigue testing machine also had load limit. In the meanwhile, a gas metal arc-welding process was utilized for preparing the butt joints coupons. The design dimension was shown in Fig. 2.

The A-type frame material under investigation is SAE 970X high strength low alloy steel under quenches and tempered conditions. After specimens were finished, their surface must not be injured, especially on the surface of welding seam, which were not allowed to be scratched, bruised and machined along lateral direction.

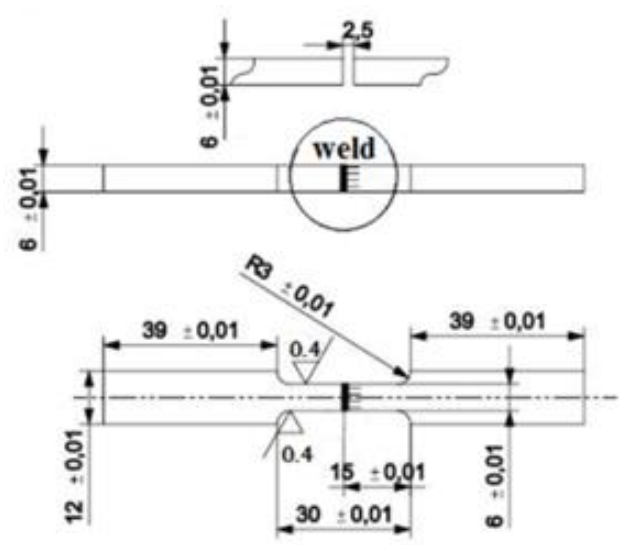

Fig. 2 Specimen geometry of weld material (all dimensions in $\mathrm{mm}$, roughness in micro meters)

\subsection{Tensile tests}

The monotonic tensile tests of flat dog-bone specimens were done with MTS 810 material testing system. Its dynamic load capacity is $\pm 100 \mathrm{kN}$ and the measurement precision is $\pm 0.5 \%$. The monotonic tensile tests were run under displacement control at the rate of $0.025 \mathrm{~mm} / \mathrm{sec}$, until specimens were snapped with axial monotonic tensile load. An Instron uniaxial extensometer with a $12.5 \mathrm{~mm}$ gauge length and $\mathrm{a} \pm 5.0 \mathrm{~mm}$ axial extension was utilized for measuring the strain. The monotonic tensile properties are listed in Table 1 .

Table 1

Mechanical properties of butt joint

\begin{tabular}{|c|c|}
\hline Material properties & Parameters \\
\hline Young's modulus $(\mathrm{MPa})$ & $2.10 \times 10^{5}$ \\
\hline Yield strength $(\mathrm{MPa})$ & 456 \\
\hline Tensile strength $(\mathrm{MPa})$ & 615.9 \\
\hline Elongation rate $(\%)$ & 18.1 \\
\hline True fracture stress $(\mathrm{MPa})$ & 24 \\
\hline True fracture strain $(\mathrm{mm} / \mathrm{mm})$ & 0.279 \\
\hline
\end{tabular}

\subsection{Cyclic tests}

To calculate the elastic and plastic mechanical responses of welded A-type frame, the cyclic mechanical properties also need. The fatigue tests under strain control was conducted and some results had discussed in my previous work [1]. The cyclic elastic strain and cyclic plastic strain and their stress values could obtain from the fatigue life testing results, and the cyclic stress and strain curve could be fitted by material constitutive relationship. In this paper, the Ramberg-Osgood equation was chosen to fit cyclic responses of welded joints. The Ramberg-Osgood coefficients were calculated for the weld material by fitting a curve with power equation to experimental data, as shown in Fig. 3. The material parameters were listed in Table 2.

Table2

Material parameters of butt joint

\begin{tabular}{|l|l|c|}
\hline & $K^{\prime}, \mathrm{MPa}$ & $n^{\prime}$ \\
\hline Welding seam & 860.99 & 0.1792 \\
\hline
\end{tabular}




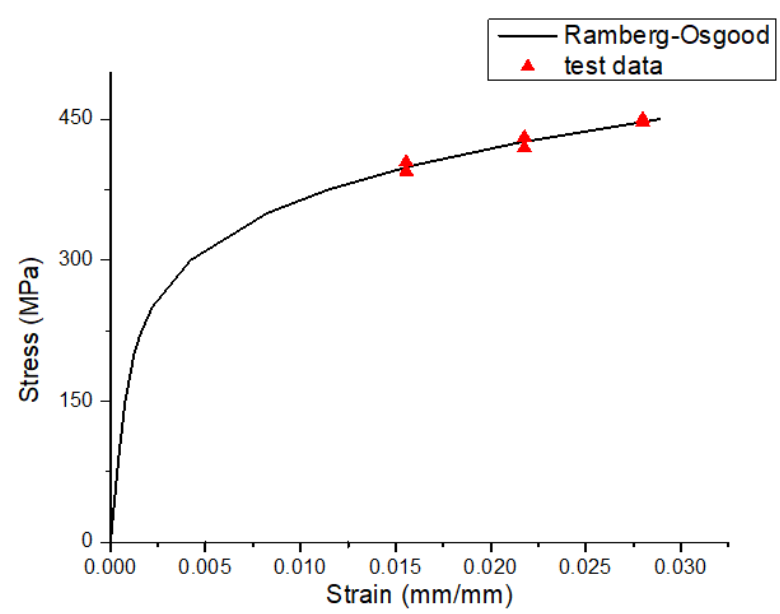

Fig. 3 Cyclic stress-strain response

\section{Finite element modelling of A type-frame}

\subsection{Multibody dynamics analysis}

\subsubsection{Multibody dynamics modelling}

To obtain the load information at different connection sites between A-type frame and frame, the rigid and flexible coupling multi-body dynamics model for whole electric wheel dump truck was generated based on multibody dynamics theory. The A-type frame and frame were bearing components with certain deformation, so both of them were identified as flexible bodies in the model. The corresponding kinematic pairs of remaining rigid bodies were established at connection sites between them. In the meanwhile, the non-linear stiffness and damping characteristics of hydro pneumatic suspension were expressed by AKISPL and BISTOP function in software ADAMS. The tire UA model was utilized to describe the mechanical properties including three directional stiffness fitted by some experimental data from Michelin. Based on sinusoidal wave superposition method, the E-class two-dimensional pavement roughness model was built in software MATLAB to generate random road surface data [1]. The whole multibody dynamics model included 41 rigid parts and 2 flexible parts, and 63 kinematic pairs and 4 contact pairs were also involved in the model, as shown in Fig. 4.

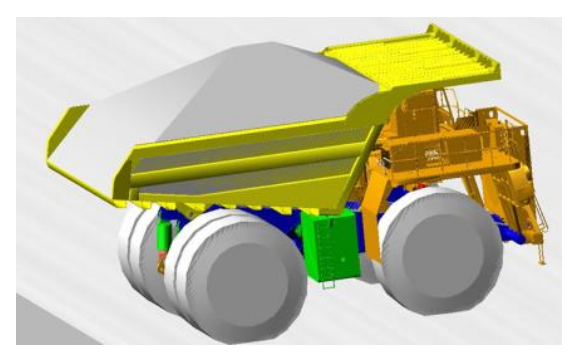

Fig. 4 Multi-body dynamics model

\subsubsection{Load time history}

The accuracy of this multi-body dynamics model was verified through comparing simulated acceleration of seat and cab floor both in time domain and in frequency domain with tested results, discussed in my previous work [1]. In this paper, the whole truck model at the speed of $20 \mathrm{~km} / \mathrm{h}$ was simulated under two conditions of random horizontal road running and downhill and turning braking with full load. The force time history at connection site of front traction joint under condition of downhill and turning braking with full load was shown in Fig. 5. The simulated time on the horizontal road surface was $20 \mathrm{~s}$, and the other one was $16 \mathrm{~s}$. It was worth mentioning that the unstable force time history of first $2 \mathrm{~s}$ on the downhill and turning road surface was deleted. In the meanwhile, in order to calculate elastic and plastic mechanical behavior under cyclic load, such as loading, unloading, reloading, it needed to simplify the load time history at different connection sites. The equivalent force loading history at connection site of front traction joint under condition of downhill and turning braking with full load was shown in Fig. 6.

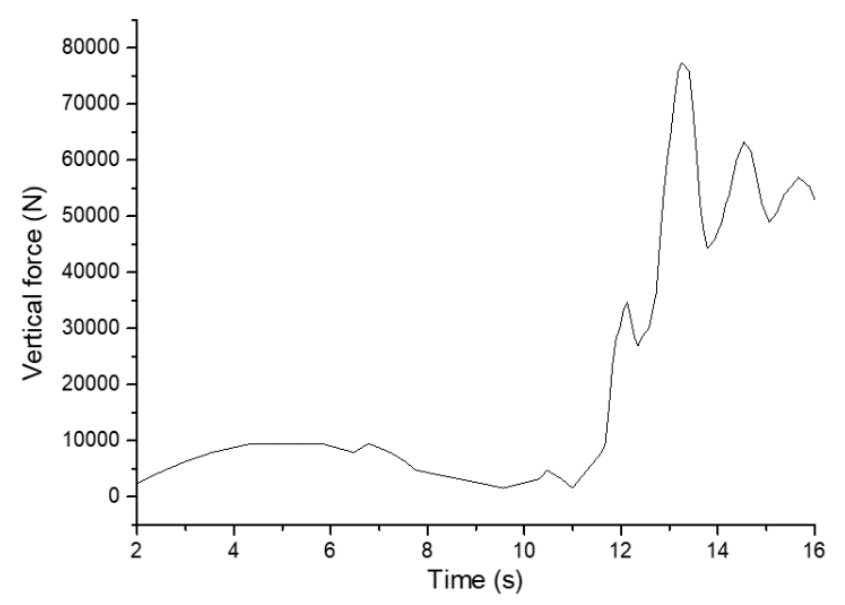

Fig. 5 Force time history at connection site of front traction joint on downhill and turning road surface

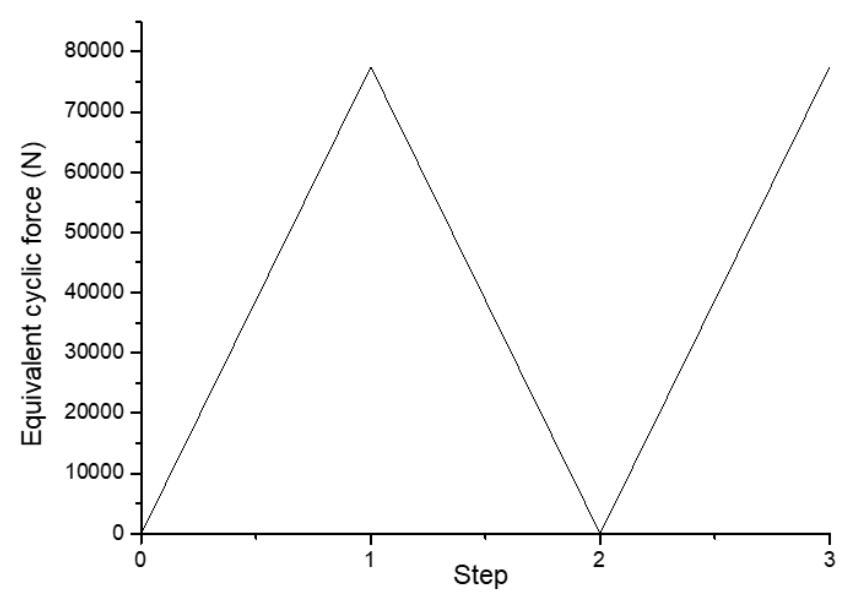

Fig. 6 Equivalent loading history at connection site of front traction joint on downhill and turning road surface

4.2. A-type frame finite element modeling and verification

\subsubsection{Modeling and stress analysis}

The A-type frame was welded by loads of high strength steel plates. Some mounting holes, process holes, chamfers and transition fillets in A-type frame were neglected in finite element modeling, because these features would increase calculation time and reduce mesh quality. The finite element model had 134564 nodes and 84948 elements, which included 824046 C3D8 elements and 2902 C3D6 elements, shown in Fig. 7. In the picture, $A 1$ was at connection site of front traction joint and $F 1$ was its vertical 
force, and $A 2$ was at connection site of left turning joint and $F 2$ was its steering force, and $A 3$ was at connection site of right turning joint and $F 3$ was its governing steering force, and $A 4$ was at connection site of front lateral stabilizer joint and $F 4$ was its lateral force, and $A 5$ was at connection site of left and right sprung joint.

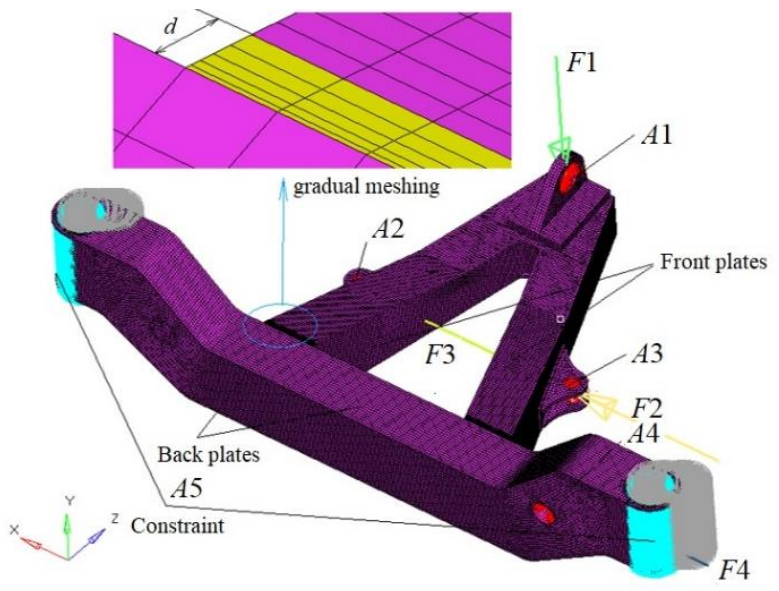

Fig. 7 Finite element model of welded A-type frame

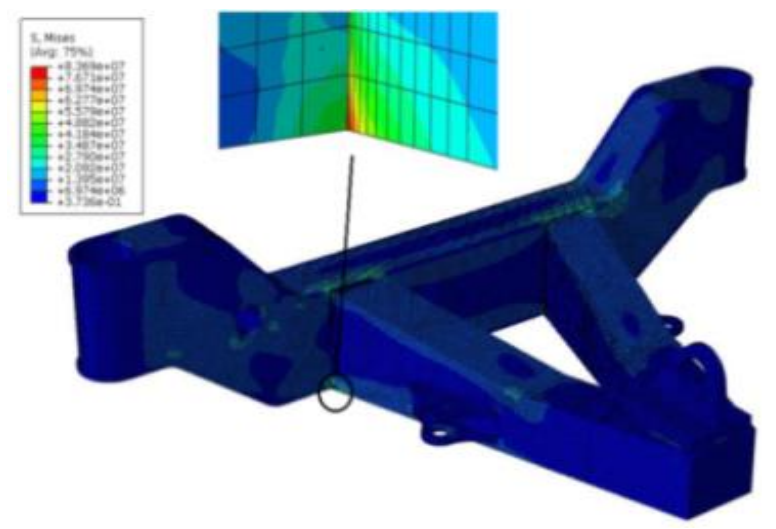

Fig. 8 Von-Mises stress contour of welded A-type frame, units in $\mathrm{Pa}$

In order to calculate mechanical responses of Atype frame under condition of random horizontal road running with full load, the static stress analysis was conducted. Its material properties came from the Table 1, and the maximum force at $A 1, A 2, A 3$ and $A 4$ connection sites under con- dition of random horizontal road running with full load obtained from multi-body dynamics analysis was applied, and the degree of freedom at $A 5$ connection site was all constrained. The Von-Mises stress contour of welded A-type frame was shown in Fig. 8. The maximum stress from simulated results was located at right bottom junction site between front plates and back plates, and it was $83.6 \mathrm{MPa}$. In the meanwhile, the location at left and right top junction site was also high stress region.

\subsubsection{Verification of A-type frame finite element model}

In order to testify accuracy of finite element model, the stress level of A-type frame on the random horizontal mine road surface was tested. And an example of the local strain gauge layout was shown in Fig.9.

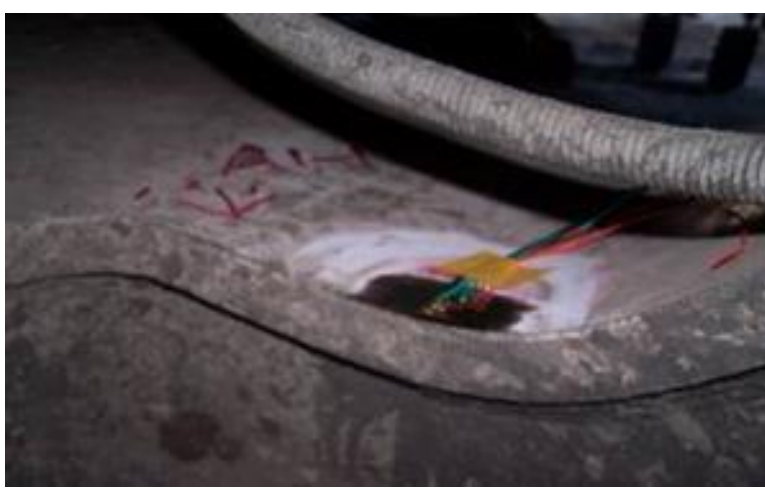

Fig. 9 Layout of one strain gauge

The principal stress values were obtained from the finite element analysis using software ABAQUS. The maximum principal stress results were compared with experimental measurements, listed in Table 3. The absolute error at measurement point $\underline{A} 2-1$ and $A 2-2$ was both around $25 \%$. The reason for large error was neglecting turning force at connection site $A 2$ and $A 3$ under condition of random horizontal road running with full load in finite element analysis, but there possibly were local stresses because of uneven forces from partial loading of goods in actual working. The absolute error at measurement point $A 4-1$ and $A 4-2$ was both around $12 \%$. The reason for this large error may be over constraint at connection site $A 5$. All other FE results agreed very well with measurement.

Table 3

Comparison of simulated and experimentally measured principal stresses, units in MPa

\begin{tabular}{|c|c|c|c|c|c|c|c|c|c|}
\hline & $A 1-1$ & $A 1-2$ & $A 2-1$ & $A 2-2$ & $A 3-1$ & $A 3-2$ & $A 4-1$ & $A 4-2$ & $A 5$ \\
\hline Simulation & 49 & 52 & 11 & 9 & 84 & 79 & 21 & 18 & 25 \\
\hline Experiment & 46 & 50 & 15 & 12 & 80 & 75 & 19 & 16 & 23 \\
\hline Error & $6.5 \%$ & $4.0 \%$ & $26.7 \%$ & $25 \%$ & $5.0 \%$ & $5.3 \%$ & $15.7 \%$ & $12.5 \%$ & $8.0 \%$ \\
\hline
\end{tabular}

\section{Fuzzy fatigue reliability analysis based on response surface method}

\subsection{Random variables and fuzzy variable}

There are many parameters associated with fatigue reliability analysis of A-type frame, such as material properties, structural dimensions and loads et al. However, it is difficult to build parameterized geometry model owing to its complex structure and huge dimensions, and thence struc- tural dimension of A-type frame was considered as deterministic variable. According to simulated results of A-type frame from multi-body dynamics analysis, its bearing forces mainly came from lateral force at connection site of front lateral stabilizer joint, vertical force at connection site of front traction joint, and turning force at connection site of left and right turning joint, which were regarded as random variables in virtue of those loads' randomness. In the meanwhile, material parameters were another key to calculate fatigue reliability of welded A-type frame. It is worth mentioning that there are two stages for calculating elastic and 
plastic mechanical behaviors of welded A-type frame. The Young's modulus $E$ and Poisson's ratio $v$ were material parameters for calculating stress-strain response in elastic stage, and cyclic strength coefficient $K^{\prime}$ and cyclic strain hardening exponent $n^{\prime}$ were ones for calculating stressstrain response in plastic stage, which were considered as random variables as well. In addition, the fatigue strength of welding seam depends on weld's quality, but there are differences because of different welding technology level for technical staffs. Therefore, its fatigue strength had some fuzziness, and was defined as fuzzy variable. The total eight random variables were input variables, and one fuzzy variable was design variable.

\subsection{Fuzzy fatigue reliability performance}

\subsubsection{Sample points}

In statistics, standard deviation is used to measure variability of sample points, but it is hard to totally reflect dispersion of sample points. In this paper, variation coefficients of random variables were introduced to estimate dispersion of sample points, and so that mean and standard deviation are both taken into account. The variation coefficient of sample points is expressed as following equation:

$$
\delta=\sigma / \mu,
$$

where: $\sigma$ is mean and $\mu$ is standard deviation.

According to some references [10], variation coefficients of Young's Modulus $E$ and Poisson's ratio $v$ were both
0.03 , and the mean value were $201 \mathrm{GPa}$ and 0.3 , respectively. However, variation coefficients of cyclic strength coefficient $K^{\prime}$ and cyclic strain hardening exponent $n^{\prime}$ were slightly larger than variation coefficients mentioned above, reaching to be 0.04 , and their mean values were $860.99 \mathrm{MPa}$ and 0.1792 . Meanwhile, variation coefficients of maximum force $F 1, F 2, \mathrm{~F} 3$ and $F 4$ were all 0.3 , and their mean values were $77500 \mathrm{~N}, 22500 \mathrm{~N}, 22500 \mathrm{~N}$ and $62500 \mathrm{~N}$, respectively. All random variables were normal distribution. In general, the fuzzy fatigue reliability of A-type frame was critical parameter for analyzing fatigue reliability performances, which could be regarded as output variable. However, the mathematical model of fuzzy reliability was difficult to get directly. According to traditional stress-strength interference model, the maximum Von-Mises stress of welded Atype frame applied with cyclic loading under condition of downhill and turning braking with full load was considered as output variable for establishing fuzzy fatigue reliability performance function of welded A-type frame. In the meanwhile, the relationship between output variable and input variables was fitted based on response surface method. The fifty sample points of eight random variables were obtained based on Latin hypercube method, and only four groups of data were listed in Table 4. According to sample points of input variables, the elastic and plastic mechanical behaviors of welded A-type frame under equivalent cyclic load shown in Fig. 10 were solved in software ABAQUS, and the corresponding partial output variable values were also listed in Table 4.

Sample points and its response value

\begin{tabular}{|c|c|c|c|c|c|c|c|c|c|}
\hline $\begin{array}{c}\text { Sam- } \\
\text { ple } \\
\text { points }\end{array}$ & $\begin{array}{c}\text { Young's } \\
\text { modulus } \\
E,(\mathrm{GPa})\end{array}$ & $\begin{array}{c}\text { Pois- } \\
\text { son's ra- } \\
\text { tio } v\end{array}$ & $\begin{array}{c}\text { Cyclic } \\
\text { strength } \\
\text { coeffi- } \\
\text { cient } K^{\prime} \\
(\mathrm{MPa})\end{array}$ & $\begin{array}{c}\text { Cyclic } \\
\text { strain hard- } \\
\text { ening expo- } \\
\text { nent } n^{\prime}\end{array}$ & $\begin{array}{c}\text { Maximum } \\
\text { Force } F 1 \\
(\mathrm{~N})\end{array}$ & $\begin{array}{c}\text { Maxi- } \\
\text { mum } \\
\text { Force } F 2 \\
(\mathrm{~N})\end{array}$ & $\begin{array}{c}\text { Maxi- } \\
\text { mum } \\
\text { Force } F 3 \\
(\mathrm{~N})\end{array}$ & $\begin{array}{c}\text { Maxi- } \\
\text { mum } \\
\text { Force } F 4 \\
(\mathrm{~N})\end{array}$ & $\begin{array}{c}\text { Maximum } \\
\text { Von-Mises } \\
\text { Stress } y(\mathrm{MPa})\end{array}$ \\
\hline 1 & 205.3 & 0.305 & 835.5 & 0.182 & 80551 & 24992 & 24184 & 71684 & 138.4 \\
\hline$\ldots \ldots$ & 204.4 & 0.296 & 825.3 & 0.183 & 69286 & 22298 & 25531 & 62296 & 121.9 \\
\hline 49 & 204.6 & $\ldots \ldots$. & $\ldots \ldots$. & $\ldots \ldots$ & $\ldots \ldots$ & $\ldots \ldots$ & $\ldots \ldots$ & $\ldots \ldots$ & $\ldots \ldots$ \\
\hline 50 & 204.1 & 0.309 & 847.7 & 0.176 & 82429 & 24184 & 20008 & 53316 & 138.6 \\
\hline
\end{tabular}

5.2.2. Establishment of performance function
Based on response surface method, the fuzzy fatigue reliability performance function of welded A-type frame is expressed as following equation:

$$
\begin{aligned}
& y=90.6808+0.0021 x 1-168.7607 x 2-0.05 \times 3-2997.9914 x 4+0.001 \times 5-0.0008 x 6+0.0022 x 7+ \\
& +0.00028 x 8-8.7072 e-9 x 1^{2}+803.6045 x 2^{2}-2.2164 e-5 x 3^{2}+5044.2594 x 4^{2}+9.6219 e-10 x 5^{2}- \\
& -1.8729 e-9 x 6^{2}-1.8545 e-8 x 7^{2}-1.5586 e-9 x 8^{2}-0.0028 x 1 \times 2+1.9523 x 1 x 3+0.0087 x 1 x 4+8.3739 e- \\
& -10 x 1 \times 5+2.4638 e-8 \times 1 \times 6-8.1652 e-9 x 1 \times 7+4.9362 e-9 x 1 \times 8+0.2348 \times 2 \times 3-471.623 x 2 \times 4+ \\
& +0.007 \times 2 \times 5+0.00076 \times 2 \times 6-0.001 \times 2 \times 7+0.00088 \times 2 \times 8+0.1054 \times 3 \times 4-1.1317 e-7 \times 3 \times 5-1.0085 e-6 \times 3 \times 6+ \\
& +3.0944 e-7 \times 3 \times 7-2.7844 e-7 \times 3 \times 8+0.0006 x 4 x 5-0.01484 x 4 x 6+0.0045 x 4 x 7-0.0052 x 4 x 8+1.6174 e- \\
& -9 \times 5 \times 6-2.2463 e-9 \times 5 \times 7-1.3421 e-10 \times 5 \times 8+9.9652 e-10 x 6 \times 7-1.0516 x 6 \times 8+3.0322 \times 7 \times 8 \text {, }
\end{aligned}
$$

where all coefficients were rounded, $y$ was equivalent VonMises stress, $x 1, x 2, x 3$ and $x 4$ were Young's modulus, Poisson's ratio, cyclic strength coefficient and cyclic strain hardening exponent, respectively. In the meanwhile, $x 5, x 6, x 7$ and $x 8$ were maximum force $F 1, F 2, F 3$ and $F 4$, respectively.

\subsection{Fuzzy fatigue reliability assessment}

In this paper, the calculation equations of failure probability $F_{i}$ were illustrated in the following part, when fuzzy variable reference functions were liner distribution, normal distribution, and parabolic distribution, respectively. 
The fuzzy variable could be described like this $(m, \alpha, \beta)$ [11]. The parameter $m$ was mean value of response values, and was calculated to be $132 \mathrm{MPa}$. The failure probability $F_{i}$ with fuzzy variable reference function being liner distribution was expressed like this:

$F_{i}=\left\{\begin{array}{ll}\frac{m-Y_{i}}{\alpha+\beta} \ln \left[1-L\left(Y_{i}\right)\right]+\frac{\alpha}{\alpha+\beta} L\left(Y_{i}\right) & \left(Y_{i} \leq m\right) \\ \frac{m-Y_{i}}{\alpha+\beta} \ln \left[1-R\left(Y_{i}\right)\right]+1-\frac{\beta}{\alpha+\beta} R\left(Y_{i}\right) & \left(Y_{i}>m\right)\end{array}\right.$,

where: $L()$ and $R($ ) were reference function, $\alpha$ and $\beta$ were left distribution parameter and right distribution parameter, and $Y_{i}$ was the corresponding response value. The failure probability $F_{i}$ with fuzzy variable reference function being normal distribution and parabolic distribution were expressed in reference [12].

According to Eq. (3) and reference [12], the fuzzy fatigue reliability of welded A-type frame from three kinds of distributions was solved in software MATLAB, when all random variables were sampled with 100,000 times. The final calculated results were listed in Table 5.

In the Table 5, the fuzzy fatigue reliability with normal distribution was the same as linear distribution, and the fuzzy fatigue reliability with parabolic distribution was a little greater than the others. However, all of them were around $88 \%$, and could not meet engineering requirements of welded A-type frame. Therefore, the fuzzy fatigue reliability optimization design of welded A-type frame needed.

Table 5

Fuzzy fatigue reliability and failure probability under different membership functions

\begin{tabular}{|c|c|c|c|}
\hline & Normal distribution & Parabolic distribution & Linear distribution \\
\hline Fuzzy reliability & 0.8837 & 0.8860 & 0.8837 \\
\hline Failure probability & 0.1163 & 0.1140 & 0.1163 \\
\hline
\end{tabular}

\section{Optimization design}

\subsection{Fuzzy fatigue reliability optimization based on genetic algorithm}

In order to improve the fuzzy fatigue reliability of A-type frame under the condition of downhill and turning braking with full load, the genetic algorithm was employed on this reliability optimal design. According to the analyzed results mentioned above, reducing the maximum equivalent stress is the key factor to increase the fuzzy fatigue reliability of A-type frame. Therefore, the output variable $y$ was considered as the optimization target. Considering the actual variation range of all random variables during the manufacturing and usage process of A-type frame, the their boundary values were defined as follows: Young's Modulus $E \in[193.198,214.5]$, Poisson's ratio $v \in[0.275$, 0.325], cyclic strength coefficient $K^{\prime} \in[660.99,1060.99]$, cyclic strain hardening exponent $\quad n^{\prime} \in[0.1742, \quad 0.1842]$, force $K 1 \in[72500,82500]$, force $F 2 \in[18000,30000]$, force $F 3 \in[18000,30000]$, force $F 4 \in[40000,70000]$ and maximum equivalent stress $y \in[120,135]$.

The population size was defined to be 20 and the number of iteration was set to be 100 . After running around 21 minutes and total 2311 iterations, the optimized results were listed in the Table 6 . It could be clearly seen that the cyclic strength coefficient $K^{\prime}$ and the cyclic strain hardening exponent $n^{\prime}$ of the weldment material both increased, which reflected that good fatigue performances of the weldment material could better ensure fatigue reliability of Atype frame. In the meanwhile, the lateral force located at the connection site between A-type frame and frame obviously decreased, which implied that reducing this lateral force could be benefit for the fatigue reliability of A-type frame. The variation ranges of the remaining random variables did not exceed $10 \%$.

Table 6

Fuzzy fatigue reliability optimization results based on genetic algorithm

\begin{tabular}{|c|c|c|c|c|c|c|c|c|}
\hline & $X 1$ & $X 2$ & $X 3$ & $X 4$ & $X 5$ & $X 6$ & $X 7$ & $X 8$ \\
\hline Before optimized & 201 & 0.3 & 860.99 & 0.179 & 77500 & 22500 & 22500 & 62500 \\
\hline After optimized & 193.198 & 0.287 & 1038.8 & 0.182 & 73091 & 19253 & 19036 & 52173 \\
\hline
\end{tabular}

According to the fuzzy fatigue reliability calculation method mentioned above, the fuzzy fatigue reliability of A-type frame was again computed as Eq. (7) in software MATLAB. Then, the fuzzy fatigue reliability of A-type frame with linear and parabolic distribution was both solved according to reference [12]. The final calculated results were listed in the Table 7.

Table 7

Optimized fuzzy fatigue reliability and failure probability under different membership functions

\begin{tabular}{|c|c|c|c|}
\hline & Normal distribution & Parabolic distribution & Linear distribution \\
\hline Fuzzy reliability & 0.9836 & 0.9861 & 0.9854 \\
\hline Failure probability & 0.0164 & 0.0139 & 0.0146 \\
\hline
\end{tabular}

It was clearly seen in the Table 7 that the optmized fuzzy fatigue reliability and failure probability under different distribution of membership function all met the engineering requirements, which were all more than $98 \%$ and less than $2 \%$. This optimization design achieved the purpose on improvement of fuzzy fatigue reliability of A-type frame. On the one hand, according to the analyzed results, controlling the welding quality could be helpful for the fatigue performances of weldment material and ensure the fatigue reliability of A-type frame, because the material performances 
depended on the welding process. On the other hand, the lateral force located at the connection site between A-type frame and frame had to be lessened. Therefore, the optimization design on the bearing capacity and force status of Atype frame still needed to be carried out.

\subsection{Structural optimization design}

According to the optimized results mentioned above, reducing lateral force located at the connection site between A-type frame and frame could improve the stress distribution of A-type frame, and indirectly enhanced its fatigue reliability. However, the front lateral stabilizer was traditionally designed to be an invariable length and rigid rod, which transferred the load from frame to A-type frame, shown in Fig. 10. This rigid structure could not buffer the impact load caused by the suspension pulse, because the relative motion of those structures depended on their geometrical relationship. It was resulted in that the A-type had to confront the tough with toughness and the local stress concentration occurred. Therefore, a novel flexible rod with variable length and nonlinear stiffness was proposed in this paper to replace the traditional one, as shown in Fig. 11. In the picture 1 and 7 are both joint bearing, and 2 is piston bar, and 3 is piston bar's head, and 4 is lubrication oil, and 5 is piston cylinder, and 6 is gas, and 8 is inflatable valve, and 9 is floating piston. It is clearly seen that the new front lateral stabilizer includes piston cylinder and piston bar, which is connected with unsprung part and sprung part, respectively. When the suspension moves up and down, the length of flexible front lateral stabilizer trends to be changed, and inert gas in the piston cylinder is compressed and expanded. Then, its stiffness increases with enlarging the compression volume of the inert gas, and decreases with enlarging the expansion volume of the inert gas. In the meanwhile, this flexible structure is installed in pairs, and its stiffness in one compression side would increase with the amplification of compression pressure, while its stiffness in the other expansion side is bound to decrease with the reduction of expansion pressure. This alteration of stiffness characteristics could relieve rigid impact through the flexible device and improve the force status of A-type frame.

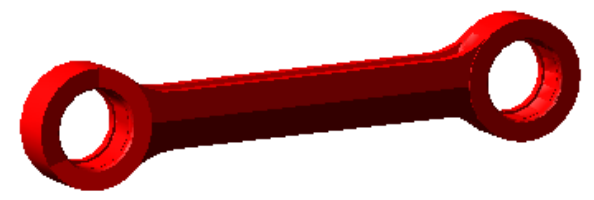

Fig. 10 Rigid front lateral stabilizer

Then, the new flexible front lateral stabilizer was added into the truck multi-body dynamics model, shown in Fig. 12. The dynamic simulation was conducted on the condition of downhill and turning braking with full load, and the speed was assigned with $20 \mathrm{~km} / \mathrm{h}$ and the simulation time was $16 \mathrm{~s}$. The lateral force time history at connection site between A-type frame and frame for two different front lateral stabilizers were shown in Fig. 13. The maximum lateral force from the flexible front lateral stabilizer dropped to be $53,600 \mathrm{~N}$, which was apparently less than the rigid one. This proposal agreed well with the optimized results of fuzzy fatigue reliability based on the genetic algorithm. Therefore, the flexible front lateral stabilizer could come true the improvement of A-type frame fatigue reliability.

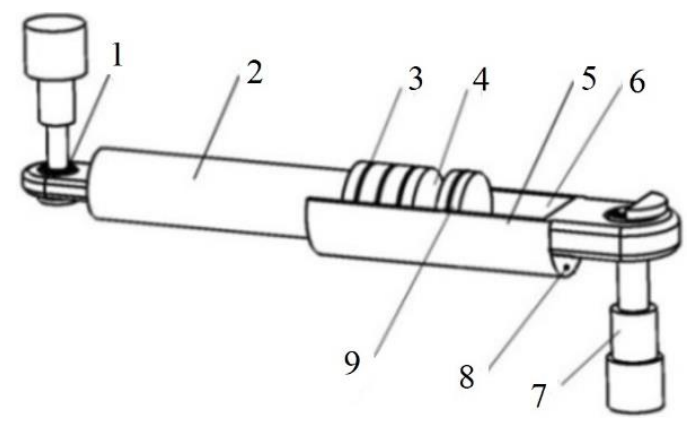

Fig. 11 Flexible front lateral stabilizer

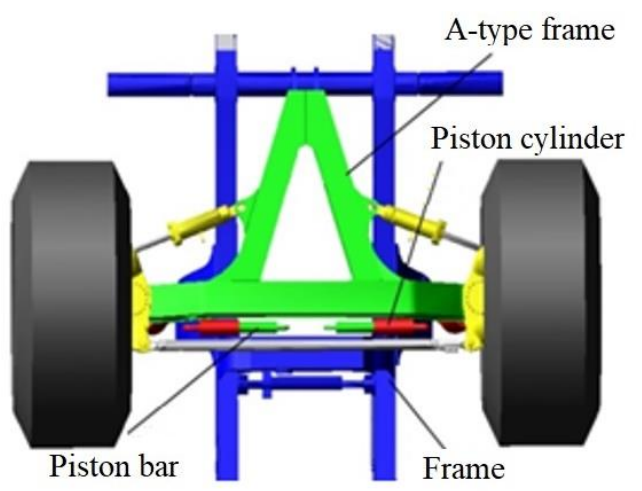

Fig. 12 Multi-body dynamics model with new stabilizers

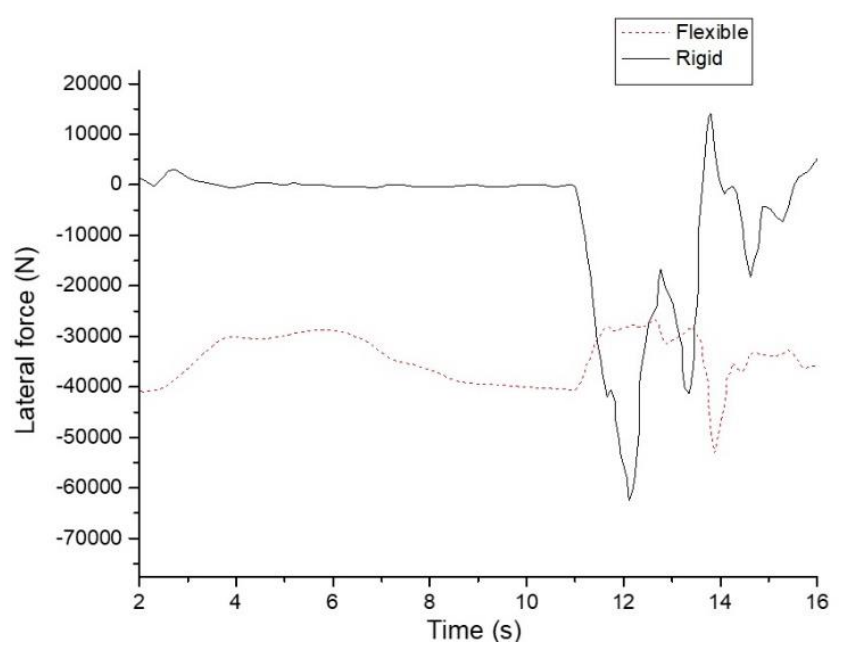

Fig. 13 Comparison of lateral force

\section{Conclusion}

In this paper, the mechanical and cyclic parameters of weld material were obtained through experimental work. The rigid and flexible coupling multi-body dynamics model of the electric wheel dump truck was constructed to calculate load information of A-type frame at critical connections. The A-type frame finite element model's accuracy was testified by the road stress test. Then, based on response surface method, the fatigue reliability performance function of A-type frame was built, and its fatigue reliability under the condition of downhill and turning braking with full load was calculated. Based on genetic algorithm, the fuzzy fatigue reliability optimization design of A-type frame was conducted, while a novel flexible lateral stabilizer was presented to improve bearing capacity and force status of Atype frame, according to the optimized results. The specific conclusions are listed as follows:

1. The uncertain factors from material parameters 
of welding seam and load information at critical connection sites were both considered. According to Monte Carlo method, the input variables, output variable and design variable were defined, respectively. A fuzzy fatigue reliability calculation method based on response surface method was constructed.

2. Based on fuzzy theory, the fatigue reliability of A-type frame under the condition of downhill and turning braking with full load was estimated, which found that its fatigue reliability under severe working conditions was less than $90 \%$. Then, based on genetic algorithm, the fuzzy fatigue reliability optimization design of A-type frame was conducted, while the fatigue reliability of the optimized Atype frame was increased to be over $98 \%$.

3. According to the optimized results from genetic algorithm, a new flexible front lateral stabilizer was suggested in this paper, which could reduce the lateral force at the connection site between the A-type frame and the frame. This optimization device was in accordance with the optimized results, and bearing capacity and force status of Atype frame were both bettered, which fully guaranteed the fatigue reliability performance of A-type frame.

\section{Acknowledgment}

The authors gratefully thank for the support of the Hunan Province Natural Science Foundation (Grant No.: 2017JJ3059 and 2018JJ4060) and China Postdoctoral Science Foundation (Grant No.: 2017M622569) and Open Foundation of State Key Laboratory of Advanced Design and Manufacturing for Vehicle Body (Grant No.: 31715012).

\section{References}

1. Gu, Z.Q.; Mi, C.J.; Ding, Z.P.; Zhang, Y.; Liu, S.C.; Nie, D.Z. 2016. An energy-based fatigue life prediction of a mining truck welded frame, Journal of Mechanical Science and Technology 30(8): 3615-3624. http://dx.doi.org/10.1007/s12206-016-0722-4.

2. Li, Z.; Niu, J.H.; Li, H.G. 2014. Analysis on fracture causes of sub-frame of a type of dump truck, Applied Mechanics and Materials 668-669: 142-146.

http://dx.doi.org/10.4028/www.scientific.net/AMM.668-669.142.

3. Li, S.H.; Wang, Y.J. 2012. Welding process optimization on frame of off-highway mining dump truck, Welding Technology 41(6): 55-57.

http://dx.doi.org/10.3969/j.issn.1002025X.2012.06.017.

4. Dong, Y. G. 2000. Mechanical fuzzy reliability design, Mechanical Industry Publishing, Beijing, China. http://dx.doi.org/10.3969/j.issn.1000680X.2015.09.011.

5. Huang, A. H.; Zhou, J.; Qiao, H. F. 2017. Fatigue test for tension shaft of a turbofan engine, Journal of Shenyang University of Technology 39(4): 395-400. http://dx.doi.org/ 10.7688/j.issn.1000-1646.2017.04.07.

6. Yang, P.; Gu, X.K. 2013. Wave loading uncertainties and structural fatigue reliability researches for semi-submersible, Journal of Ship Mechanics 17(4): 398-410. http://dx.doi.org/10.3969/j.issn.1007-7294.2013.04.009.

7. Wang, L. B.; Peng, P. Y.; Jin, H. 2003. New method of analyzing fatigue integrated reliability of metal structure, China Railway Science 24(4): 78-81.

http://dx.doi.org/10.3321/j.issn:1001-4632.2003.04.015.

8. Gao, T.J. 2016. Uncertain analysis of A-type frame welds of mining dump truck and anti-fatigue design, $\mathrm{Hu}-$ nan University, Changsha, China.

9. Liu, Z.C.; Jiang, C.; Li, Y.; Bai, Y.C. 2015. Fatigue life optimization for spot-welded structures of vehicle body considering uncertainty of welding spots, China Mechanical Engineering 26(18): 2544-2549.

http://dx.doi.org/10.3969/j.issn.1004132X.2015.18.024.

10. Lin, G.Q.; Wang, M.T. 2011. Fatigue reliability analysis of the compressor shaft based on L-R fuzzy numbers method of fuzzy theory, Compressor Technology 229(5): 4-7. http://dx.doi.org/10.3969/j.issn.1006-2971.2011.05.002.

11. Chen, C.L.; Kuo, F.C. 1995. Design and analysis of a fuzzy logic controller, International Journal of Systems Science 72(3): 1223-1248. http://dx.doi.org/10.1016/0165-0114(94)00259-A.

12. Dong, Y.G. 2000. Fuzzy design, Mechanical Industry Publishing, Beijing, China.

\section{J. Mi, W. T. Li, W. G. Wu, X. W. Xiao \\ FUZZY FATIGUE RELIABILITY ANALYSIS AND OPTIMIZATION OF A-TYPE FRAME OF ELECTRIC WHEEL DUMP TRUCK BASED ON RESPONSE SURFACE METHOD}

S u m m a r y

In order to accurately evaluate fatigue reliability performances of A-type frame, a fuzzy fatigue reliability calculation method based on response surface method is proposed, considering the uncertainties of A-type frame in the actual manufacture and use stage. The fatigue reliability performance function of A-type frame was constructed based on response surface method to evaluate the fatigue reliability performance of A-type frame under the condition of downhill and turning braking with full load and its fatigue reliability was found to be less than $90 \%$. Then, the fuzzy fatigue reliability performance was optimized by genetic algorithm. According to the optimized results, a new flexible front lateral stabilizer for this steering system was presented, which could guarantee its fatigue reliability performance. The final fatigue reliability of the optimized A-type frame reached up to $98 \%$.

Keywords: A-type frame, fuzzy fatigue reliability, response surface method, performance function, genetic algorithm.

Received October 10, 2018 Accepted January 15, 2019 